\title{
Poblamiento y frontera en Andalucía (S.S. XIII-XV)
}

Manuel González Jiménez *

La conquista de Toledo en 1085 significó un importante salto en la recuperación del territorio. Por vez primera o casi, los cristianos lograban el control de una gran ciudad musulmana. En años anteriores se habían ocupado plazas de cierta importancia estratégica, como Lamego, Viseu $y$, especialmente, Coimbra. Pero la conquista de la antigua capital visigoda significaba desplazar la frontera hasta el Tajo. Se trataba de un punto demasiado avanzado, cuya defensa había que garantizar a toda costa. $Y$ es así como se acomete, casi simultáneamente, el poblamiento de dos zonas que desde ahora y durante más de un siglo serán las nuevas fronteras del reino castellano-leonés: las Extremaduras y la Nueva Castilla.

El futuro de los nuevos territorios fronterizos -así como el de los que pudieran incorporarse en el futuro- dependía de la capacidad de instalar en ellos a poblaciones capaces de participar eficazmente tanto en la guerra defensiva como en la ofensiva. Para conseguir estos objetivos no eran suficientes los viejos mecanismos repobladores basados en la ocupación de tierras por parte de grupos campesinos más o menos jerarquizados. Por el contrario, desde el siglo XI la instalación de pobladores estará controlada en buena medida por la corona que actuará directamente o a través de delegados regios de tanto relieve como el conde Raimundo de Borgoña, el repoblador de Ávila y Segovia.

- Universidad de Sevilla. 
El resultado de esta nueva modalidad repobladora fue el establecimiento tanto en Toledo como sobre todo en las villas de las Extremaduras de una «sociedad organizada para la guerra», en expresión afortunada de Elena Lourie. Los fueros de la zona, desde el más antiguo de Sepúlveda, hasta los de Riba de Coa o el de Cuenca, que condensa a la perfección el espíritu de las villas de la frontera extremeña. Nos presentan una sociedad de guerreros-pastores y de campesinos belicosos, entre los que no debían faltar los aventureros y delincuentes, a quienes - como se indica en el fuero de Sepúlveda de 1076- se perdonaban sus crímenes por el simple hecho de participar en la repoblación del territorio; una población, en definitiva, que había hecho de la guerra su principal industria (Gautier-Dalché).

La repoblación de Toledo y de las Extremaduras dio orígen a unas prácticas y a un tipo de sociedad llamado a prolongarse durante siglos en Andalucía y en Murcia, que fueron las zonas donde la frontera fue por más tiempo una realidad viva. Este tipo de repoblación no buscaba, como en épocas anteriores, la simple ocupación de tierras y su puesta en cultivo; por el contrario, era parte imprescindible de una operación tendente a fijar una frontera y a defenderla una vez constituida.

\section{EL NACIMIENTO DE LA FRONTERA ANDALUZA-GRANADINA}

La conquista de Andalucía en la primera mitad del siglo xIII no dio origen a una frontera formalmente definida. A la muerte de Fernando III, Castilla controlaba directamente una serie de territorios, centrados en torno al eje del Guadalquivir, y otros seguían gobernados por príncipes y autoridades musulmanas: Granada, Niebla, Murcia y Jerez. Murcia era un caso extremo de reino vasallo, pues ¿qué fronteras - aparte de las puramente formales- podía haber entre un reino que se decía vasallo y que conservaba su propio rey, en el que, sin embargo, todas las fortalezas estaban controladas por los castellanos? Tampoco estaban muy claras las cosas en las fronteras con Granada o los territorios del Guadalete. 
Aparentemente, con el sometimiento de los distintos jefes musulmanes, la reconquista había concluido. Todo el territorio de al-Andalus estaba bajo el dominio de los cristianos. Y, de esta forma, Fernando III pudo morir convencido de ello, como lo prueban las palabras que, según la Primera Crónica General, dirigió a su hijo Alfonso poco antes de morir:

«Hijo..., sennor te dexo de toda la tierra de la mar acá que los moros del rey don Rodrigo de Espanna ganado auien; e en tu sennorio fica toda: la vna conquerida, la otra tributada».

En teoría era así: los mudéjares del valle de Guadalquivir vivían sometidos a Castilla en virtud de las capitulaciones de rendición, pagando al castellano rey "sus pechos conplidos et bien parados"; los reyes moros, por su parte, pagaban sus "parias" y, llegado el caso, como sucediera en la conquista de Sevilla, prestaban al rey consilium et auxilium y se comportaban en todo como fieles vasallos, como lo manifiesta el hecho de que sus nombres aparezcan habitualmente entre los confirmantes de los privilegios y documentos más solemnes emitidos por la cancillería real. En estas circunstancias, la frontera no existía o estaba muy mal definida. A lo más, quedaban algunas estructuras defensivas organizadas en el Alto Guadalquivir al comienzo de las conquistas. Pero desde la conquista de Córdoba en 1236 y, especialmente, desde la rendición de Jaen y la entrada en vasallaje de Muhammad I (1246) tales precauciones defensivas se abandonaron ante la evidencia del hundimiento del poder almohade y la escasa resistencia que ofrecian los andalusies.

A partir de la revuelta de los mudéjares de Andalucía y Murcia en 1264 las cosas cambiaron radicalmente. Tras el sometimiento y la expulsión o exilio de la mayoría de los musulmanes todavía instalados en el valle del Guadalquivir, las relaciones con Granada - el único reino mudéjar que sobrevivió a la crisis- se establecieron sobre bases diferentes. A estos hechos habría que añadir la aparición en la zona del Estrecho de la amenaza de los benimerines, cuya presencia obligó a reforzar todo el sistema defensivo de los reinos de Córdoba y Sevilla. $Y$ de nuevo fueron las Ordenes Militares las encargadas de soportar la mayor parte del esfuerzo militar, si bien, en algunos casos, Alfonso $X$ recabó el apoyo de la nobleza asentada en la región.

Pero no convendría pensar que la frontera y, sobre todo, los mecanismos defensivos no hubieron de improvisarse tras la sorpresa de 1264 . 
De hecho, desde su misma conquista, el valle del Guadalquivir se perfiló ya como la frontera, hasta el punto de que en algunos documentos oficiales Andalucía es llamada la "frontera", cuya defensa estaba encomendada, desde 1254, a un adelantado mayor. Pero, en cualquier caso, independientemente de esto, y como ya sucediera anteriormente en otras partes, la defensa de las tierras conquistadas recaía de lleno sobre los propios repobladores asentados en la región. Las casas y tierras que habían recibido de los reyes en los repartimientos les obligaban tanto a poblar en Andalucía como a prestar servicios militares. Nada de esto era nuevo, ya que, como es sabido, desde la conquista de Toledo, el repoblador era algo más que un simple colono. Por el contrario, era la principal garantía de la definitiva ocupación de las tierras ganadas al Islam. Por ello era lógico que en Andalucía reapareciesen las antiguas categorías socio-militares de los caballeros villanos y de los peones, dentro de las cuales aparece encuadrada la totalidad de los repobladores. Cambian un poco las denominaciones, como corresponde a una nueva época y a un distinto ámbito histórico. Y, así, en la generalidad de los casos, la nueva población se agrupó en torno a tres categorías diferentes: la de los caballeros de linaje o hidalgos, pertenecientes, como los infanzones de algunos fueros extremeños, a los estratos inferiores de la nobleza, que eran, como los define un texto portugués del siglo XII, milites per naturam; la de los caballeros ciudadanos, adaptación un mundo de ciudades de la antigua denominación de caballeros villanos; y la de los peones, a quienes un texto de tiempos de Alfonso X llama «el otro pueblo».

En algunas ciudades de frontera repobladas después de 1264 tales categorías se multíplican, en razón sin duda a la condición fronteriza de la plaza repoblada. $Y$, de esta forma, en Jerez encontramos, además de las categorías básicas citadas, otras tales como los ballesteros y arqueros, los adalides, que figuran también en otras muchas ciudades del interior del valle, los almocadenes, los almogávares e, incluso, un cuerpo especial formado por cuarenta ballesteros de a caballo. En Vejer, repoblada entre 1288 y 1293, se citan además a escuderos, equiparables a los caballeros de linaje.

Pero donde se observa con mayor nitidez esta relación entre repoblación y frontera es, sin duda, en las villas de especial importancia estratégica y en las situadas en la misma frontera. En estos casos, las disposiciones genéricas sobre la obligatoriedad de participar en la de- 
fensa del territorio se vuelven mucho más explícitas de lo normal. Esto puede observarse con claridad en la carta-puebla de Alcalá de Guadaira, otorgada por Alfonso X en 1280.

Alcalá está situada a unos $20 \mathrm{Km}$. de Sevilla, defendiendo desde su impresionante fortaleza los caminos de acceso a la ciudad desde Granada o desde la zona del Estrecho de Gibraltar. Esta circunstancia mereció a la villa el calificativo de "guarda e collación de Sevilla". De acuerdo con su importancia estratégica, Alcalá dependió inicialmente de Sevilla, si bien, en 1258, fue entregada en señorio al cabildo de la Catedral Hispalense. Sin embargo, tras las tremendas incursiones realizadas por los benimerines a partir del verano de 1275. Alcalá recuperó su papel de pieza clave en la defensa de la ciudad, la cual se encargó de atender a los gastos que ocasionaba defender la villa y la fortaleza. Ello permite suponer que la primera repoblación no debió dar los resultados previstos por estar prácticamente despoblada.

Para remediar esta situación, Alfonso $X$ favoreció el paso de Alcalá a la jurisdisción de Sevilla y emitió en mayo de 1280 una carta-puebla con la que se pretendía asentar a unos 150 pobladores. Del documento sólo nos interesan las disposiciones referentes a las obligaciones militares de los nuevos pobladores, que debían habitar en el castillo «con sus cuerpos" y participar personalmente en las velas nocturnas de la fortaleza y del arrabal y realizar servicios diurnos de atalaya en el castillo. En el caso de verse obligados a vender sus propiedades, debían hacerlo a personas que cumpliesen tales obligaciones, e, igualmente, si caían cautivos de los moros, estaban autorizados a desprenderse de sus bienes para pagar el importe del rescate, pero siempre que el comprador se comprometiese a hacer "vezindat en Alcalá" y cumplir los servicios militares correspondientes (He editado esta carta puebla en mi artículo «Alcalá de Guadaira en el siglo XIII. Conquista y repoblación», Actas de las I Jornadas de historia de Alcalá de Guadaira, Alcalá 1987, 51-52.

\section{EL DERECHO FRONTERIZO}

A lo largo de la segunda mitad del siglo xill y al mismo tiempo que se organiza la defensa fronteriza, se fue perfilando todo un derecho de la frontera orientando fundamentalmente a atraer pobladores dispuestos 
a asentarse en las localidades de frontera. La base del mismo fueron las exenciones tributarias previstas en la carta-puebla de Alcalá y en otros documentos anteriores y posteriores. Por razones obvias, la documentación que permite observar mejor la formación de este derecho corresponde al sector de la frontera del Estrecho de Gibralrar, donde además se experimentaron por vez primera algunas de sus más interesantes disposiciones. Examinemos con detalle el contenido de este derecho fronterizo.

1) Exenciones Fiscales. El aspecto más general del derecho fronterizo lo constituyen las numerosas exenciones fiscales otorgadas a los pobladores ya existentes o venideros de las localidades de frontera. El cuerpo de documentación mejor escalonado y de mayor antiguedad, a través del cual puede observarse la progresión de las franquezas otorgadas por los reyes de las villas de frontera, se conserva en el Archivo Municipal de Medina Sidonia. Ya en 1268, a los pocos años de su repoblación, los peones de la villa fueron declarados exentos del diezmo real que pagaban los peones de Sevilla, a cuyo fuero estaba poblada la ciudad. Además el rey eximió a todos sus habitantes del pago de otros impuestos, excepto moneda y yantar. Unos años más tarde, en 1282, les libró de pagar montazgo «en ningund lugar de nuestro sennorío». Por último, en 1288 Sancho IV reiteró estas exenciones, ampliándolas a cualquier tipo de impuesto.

Tales franquicias tributarias se incrementarian extraordinariamente en el caso de dos importantes villas de frontera: Tarifa, conquistada por Sancho IV en 1292, y Gibraltar, ocupada por Fernando IV en 1309. Un privilegio del primer monarca, otorgado a los pobladores de Tarifa en 1292, nos informa de una gama amplísima de exenciones tales como el diezmo portazgo, veintena y cuarentena, alcabala y cualquier otro derecho que tuviese que pagar «por las cosas que leuaren o troxieren o vendieren por mar o por tierra en todos los lugares de nuestros regnos o en logares de Ordenes o de otros sennorios que son el nuestro sennorio". Y, para asegurar el abastecimiento de la villa, el rey eximió a los mercaderes cristianos, moros y judios que trajesen armas y alimentos a Tarifa del pago de cualquier tipo de impuesto comercial, y, a sus barcos, del pago de ancorage. La carta-puebla de Gibraltar, dada por Fernando IV en 1310, contiene también una amplia serie de exenciones fiscales que, a mi entender, resume casi todas las posibilidades tributarias de la época: diezmo, portazgo, alcabala, montazgo y asadura, roda y castillería, servicios, monedas y martiniegas. 
Estas exenciones se extendieron gradualmente a la mayor parte de los pueblos de la frontera, especialmente la de la alcabala, sin duda el impuesto básico del sistema fiscal castellano bajomedieval. Así, en 1351 Pedro I confirmó a los repobladores de Alcalá la Real las exenciones fiscales que les otorgara su padre Alfonso $\mathrm{XI}$, reseñando específicamente los siguentes impuestos: martiniega, infurción, marzazga, alcabala, portazgo, almojarifazgo, roda, castillería, peaje, barcaje o cualquier otro, «tributo de los que agora son puestos o se pornán daquí adelante en el nuestro sennorío por las cosas que traxieren para bastecimiento de la dicha villa e para mantenimiento de los vecinos y moradores". De 1378 es un privilegio de Enrique II otorgado para favorecer la instalación en Cote de 20 vecinos de Morón. En el mismo, el rey, teniendo en consideración que el castillo "está en frontera de moros e porque cumple mucho a servicio de Dios e nuestro e a guarda de las comarcas de enderredor", declara exentos a perpetuidad a los pobladores-soldados y a sus descendientes del pago de moneda, servicio, yantar, empréstidos, servicios de ballesteros, lanceros y galeotes y de cualquier otra clase de tributos reales. $Y$, además, les libera de pagar alcabalas por las cosas que "compraren e levaren al dicho castillo de Cote que ovieren menester para su provisión e mantenimiento e para abastecimiento del dicho castillo". Dentro de esta misma línea de exención global de impuestos realengos se inserta el privilegio dada a Antequera en 1411, en virtud del cual los pobladores estaban libres de pagar moneda, pedido, almojarifazgo, diezmo, alcabalas y cualquier otra clase de tributo.

De la extraordinaria difusión de estos privilegios nos informan hasta la saciedad los documentos fiscales del siglo xv. Así, por dar un sólo ejemplo, en el cuaderno de alcabalas de 1422 se reseñan las siguientes villas y castillos de la frontera andaluza-granadina cuyos vecinos estaban exentos de este impuesto: Tarifa, Teba, Olvera, Alcalá la Real, Alcalá de los Gazules, Cabra, Antequera, Zahara, Torre Alháquime, Cañete, Pruna, Aznalmara, Alcaudete, Jódar, La Guardia, Medina Sidonia, Lucena, Arcos, Espera y Véjer.

2) Privilegios militares. Indicábamos más arriba, al hablar de la carta-puebla de Alcalá de Guadaira, que las obligaciones militares de los habitantes de la frontera eran fundamentalmente de carácter defensivo. No obstante, otros documentos de la segunda mitad del siglo xIII aluden también a la obligación de participar en la hueste real, si bien reducen el ámbito territorial de aplicación de este servicio a la zona comprendida entre el Guadalquivir y a la mar, como se señala en un privilegio concedido por Alfonso $X$ a Medina Sidonia en 1268. Con el tiempo, aún esta 
obligación de alcance limitado desapareció, como se observa ya en la carta puebla de Gibraltar (1310).

Este mismo texto ofrece otros de los rasgos característicos de las villas fronterizas de Andalucía. Se trata, en primer lugar, de la condición de soldados de la mayor parte de la población, lo que explica que reciban anualmente del rey soldadas. A este respecto, la carta-puebla de Gibraltar establece que

«porque la villa de Gibraltar se pueda mejor guardar, mandamos que haya y 300 vecinos..., e que todos aquellos que y moran, que ayan por su soldada el ballestero de monte $45 \mathrm{mrs}$., e el ballestero de estribera 40 mrs., e el peon $35 \mathrm{mrs}$., e si fuere almocadén $50 \mathrm{mrs} .$. E si algunos destos velare encima del muro de la villa de Gibraltar, que aya además de su soldada $10 \mathrm{mrs}$. de su vela».

La documentación del siglo $x v$ nos informa con todo detalle sobre el número de pobladores-soldados y de los sueldos que percibían. Un extraordinario testimonio documental publicado por M. A. Vilaplana Montes ( Un ajuste de cuentas del alcabalero mayor de Sevilla Pedro Ortiz (1420)", Historia. Instituciones. Documentos, 1, 1974, pp.427-501) permite evaluar tanto la población de iure de algunas plazas fronterizas, como el importe de las soldadas pagadas por los contadores reales. He aquí algunos datos:

Tarifa (1402)

60 caballeros........... 57.600 mrs.

200 ballesteros $43.200 \mathrm{mrs}$.

220 lanceros

Además, el rey satisfacía los sueldos de los oficiales del concejo, de nueve alcaides "que están en las iorres", de ocho «atajadores", de ocho comitres, de un "engeniero" y de un maestro mayor albañil, seis carpinteros y tres aserradores, 12 albañiles, 11 almocadenes, un maestro «de fazer ballestas", un maestro "fojero" y un ballestero "para adobar $e$ reparar las ballestas que son en el Alcáçar». También pagaba el rey las "guardas y escuchas en la paz" y los salarios de los que velaban y rondaban los muros de la villa. 
Teba (1407)

25 caballeros

$15.000 \mathrm{mrs}$.

60 ballesteros ........... 18.000 mrs.

215 lanceros............. $215.000 \mathrm{mrs}$.

Más las velas y rondas mensuales, y el sueldo de un «maestro de fazer truenos".

Alcalá de los Gazules .... 54 caballeros

60 ballesteros

70 lanceros

Total

$77.520 \mathrm{mrs}$.

Cañete

20 lanzas

10 jinetes

20 ballesteros

10 lanceros

La defensa de Antequera, conquistada en septiembre de 1410, exigió también un importaníe esfuerzo económico y humano. La guarnición prevista ascendía a 620 vecinos - 120 caballeros, 200 lanceros y 300 ballesteros-, cuyas «pagas" ascendían a 369.020 mrs., a lo que añade el importe de las «levas de pan» que sumaban mas de $500.000 \mathrm{mrs}$. (F. AlIJO HIDALGo. "Privilegios a las plazas fronterizas con el reino de Granada", Estudios sobre Málaga y el Reino de Granada en el V Centenario de su Conquista, Málaga 1988, p. 29).

Estas cifras, y otras que pudieran deducirse del mismo documento, corresponden a años de guerra, y por ello resulta muy defícil determinar cuántos de estos soldados eran realmente vecinos. Porque lo cierto es que Teba, por poner un ejemplo, nunca tuvo en la Edad Media 300 vecinos, lo mismo podría decirse de otras localidades como Zahara o Torre Alháquime, a la que en 1410 se atribuyen 160 vecinos. No obstante, en ocasiones, los datos de esta índole parecen aproximarse bastante a la realidad. Es el caso, por ejemplo, de Olvera que contaba en 1472 con 110 vecinos-soldados, distribuidos en 20 caballeros, 24 ballesteros y 66 lanceros (M. RoJAs, Olvera en la Baja Edad Media, Cádiz 1987, p. 117)

Otro de los rasgos específicos de las villas fronterizas era que sus habitantes recibían, de acuerdo con la condición militar de cada uno, 
consignaciones anuales de cereales, como las que se suministraban a Antequera y a las que hemos aludido más arriba. El sistema, que alcanzó un gran desarrollo a partir de la segunda mitad del siglo XIV, parece que se esbozó en el reinado de Alfonso XI, aunque de forma excepcional ya se puso en práctica en tiempos de Sancho IV. La primera mención segura la encontramos en un privilegio dado en 1335 a los pobladores del castillo de Tiscar, en el reino de Jaen. También consta de que el rey abastecía a una serie de villas recién conquistadas, como Priego, Rute y Alcalá la Real. De esta última sabemos que se entregaban a cada uno de los 50 caballeros instalados en la villa dos fanegas de trigo y cinco de cebada, mientras que cada uno de los 150 ballesteros y 300 lanceros - lo mismo cada uno de los 10 lanceros y 20 ballesteros que formában la guarnición del castillo de Locubín- recibían dos fanegas de trigo mensuales (C. JuAn LOVERA; Colección Diplomática Medieval de Alcalá la Real, I, Alcalá la Real 1988, doc. n. 11).

La documentación posterior es muy abundante y rica en detalles. A través de la misma podemos conocer con exactitud el funcionamiento del sistema de las levas del pan a las villas fronterizas. Así, de acuerdo con la documentación conservada en el Archivo Municipal de Carmona, entre enero de 1384 y febrero de 1385 , se enviaron a Olvera por lo menos 3.360 fanegas de trigo y 2.848 de cebada. El número de expediciones documentadas es de doce, y a costa del rey corrían también los salarios de los arrieros que efectuaban el transporte, a razón de $12 \mathrm{mrs}$. por cada legua, y de la escolta armada de caballeros que acompañaba a la recua, a razón de $30 \mathrm{mrs}$./caballero por expedición (M. GonzÁLEZ JiMÉnEZ: Catálogo de la documentación medieval de Archivo Municipal de Carmona, I, Sevilla $1975, \mathrm{nn} .44,47-50$ y 53 ).

La asociación de soldadas y consignacinos de cereales a los pobladores-soldados de las villas y castillos fronterizos se observa a la perfección en un interesante albalá otorgado por Enrique II en 1378 a los pobladores de Morón y Cote. En su virtud, y a cambio de mantener cabailos y armas, morar permanentemente en la villa y efectuar periódicamente los alardes, "segunt es acostumbrado de ser fazer en las otras nuestras villas e castillos fronteros", los 30 caballeros de Morón recibían cada años $200 \mathrm{mrs}$. de soldada y cebada suficiente para mantener "buenos cavallos". Los almocadenes, encargados de efectuar los rastros o averiguación de dónde procedían las incursiones que pudieran efectuar los moros sobre territorio de Morón, recibían del rey $500 \mathrm{mrs}$. y, además, "su mantenimiento, porque estén continuadamente en la dicha villa». Por último, los 20 vecinos del castillo de Cote percibían al año 120 mrs. y 12 
fanegas de trigo (M. GarCía FERnÁNDEZ: «La carta-puebla del castillo de Cote. Estudio y edición», Archivo Hispalense, 214, 1977, p. 67).

3) El privilegio de homicianos. Sin duda el rasgo más característico del derecho fronterizo fue el llamado privilegio de homicianos, cuyos precedentes se encuentran en el fuero de Sepúlveda de 1076. Olvidada o en desuso durante siglos, Fernando IV renueva esta práctica al conceder en 1310 a Gibraltar su carta-puebla. A partir de este momento, y al objeto de impulsar la defensa y la repoblación de las villas fronterizas, el derecho de asilo va alcanzar una extraordinaria difusión. El texto de Gibraltar dice así:

...todos aquellos que se fueren para Gibraltar e que sean y vecinos e moradores, quier sean golfines o ladrones, o hayan muerto homes, e otros homes quialesquier malhechores que sean, o muger casada que fuya a su marido..., que sean defendidos e amparados de muerte".

Del privilegio de homicianos se exceptúan tan sólo determinados delitos, como la traición o la entrega de castillos «contra su sennor», el quebrantamiento de la «tregua o paz del rey», y el rapto de la «muger de su sennor».

Durante el reinado de Alfonso XI el privilegio de homicianos se extendió por toda la frontera: Alcaudete (1226), Olvera (1327) y Tarifa (1333), en atención a que la villa estaba, como se dice en el texto de la concesión, "muy cerca de los moros e han menester muchas gentes para defendimiento della». En este último caso y lo mismo que en el privilegio de Gibraltar, el perdón afectaba a toda clase de delitos o de maleficios, como homicidios o muertes de hombres, robos y tomas, etc., exceptuándose solamente los delitos de alevosía y de traición. Pero en esta nueva serie de privilegios de homicianos aparece una novedad de importancia: por vez primera se fija el tiempo que había que residir en la frontera para que los delitos se considerasen legalmente prescritos, «un anno et un día». Otra novedad, que consta en la carta-puebla de Olvera, es la posibilidad de servir la villa de refugio temporal - por cuatro añosa aquéllos que eran perseguidos por deudas.

Otras villas fronterizas, como las de Alcalá la Real, Priego, Teba y Ardales, Antequera, Archidona y Jimena recibieron el mismo privilegio, al que, con el paso del tiempo, fueron añadiéndose nuevas precisiones, 
como la establecida en las Cortes de Toledo de 1480, de que la residencia en las villas de la frontera fuese por "vn anno entero" - no obstante, en Antequera, Teba-Ardales y Jimena el tiempo se redujo por privilegio especial a sólo diez meses-, o la de incluir entre los delitos exceptuados del perdón el de "muerte segura» $u$ homicidio premeditado, o excluir de su beneficio los delitos cometidos a menos de cuarenta leguas de la frontera (Cortes de León y Castilla IV, pp. 176-177). Un caso interesante de difusión del privilegio de homicianos más allá de la frontera tradicional es la concesión del mismo a Salobreña en octubre de 1490, que estudiara R. SerRa Ruiz (El derecho de asilo en los castillos fronterizos de la reconquista, Murcia 1965). Este mismo privilegio, y por las mismas razones -porque algunas villas de las que estaban conquistando durante la guerra de Granada estaban, como Salobreña, "mucho metida en la tierra de los dichos moros»- se otorgó en 1484 a Alhama, rebajándose el tiempo de residencia a ocho meses. (Cfr. F. ALIJo Ob. cit., p.33).

Con el privilegio de homicianos no pretendía, o, al menos, no era esta su primera finalidad, acentuar el poblamiento de las villas de frontera, sino más bien su defensa. No obstante, indirectamente, pudo servir para aumentar la población, siquiera de una forma oscilante y coyuntural, de las localidades fronterizas.

A pesar de tales privilegios, la frontera se pobló con muchas dificultades. Y, así, sabemos que Medina Sidonia, que había sido repoblada una y otra vez, no tenía más de ciento cincuenta vecinos. El caso de Antequera es todavía más espectacular, si se tiene en cuenta que corresponde a finales del siglo xv. En efecto, cuando se producen los repartos definitivos de tierras ordenados por los Reyes Católicos y realizados por el bachiller Serrano, sólo constan de 221 "vecinos naturales», de los 620 vecinos previstos en la carta-puebla de 1410 . Y lo sorprendente del caso es que tal cifra ni tan siquiera se alcanzó con la llegada de los vecinos nuevos que figuran en el libro del repartimiento (F. ALiso: Antequera y su tierra. 1410-1510. Libro de repartimiento, Málaga 1093, p.93). Señal evidente de que la frontera, a pesar de la política de privilegios y exenciones desplegada a lo largo de más de dos siglos por la Corona, seguía siendo un factor que condicionaba muy negativamente el poblamiento de las villas fronterizas. Por ello, no deja de ser significativo el hecho de que el final de la guerra de Granada y la desaparición de la frontera provocasen a lo largo de la misma una verdadera oleada de nuevas repoblaciones, especialmente importantes en la «banda morisca» sevillana y en el reino 
de Jaén (A. Collantes DE TERÁN: "Nuevas poblaciones del siglo XV en el reino de Sevilla", Cuadernos de Historia, 7, Madrid 1977, ha estudiado detenidamente el fenómeno de Villamartín, Campillos, Paradas, Puebla de Cazalla y Paterna de Ribera). Y está por estudiar la expansión urbana de villas fronterizas tan significativas como Antequera, Estepa, Osuna, Morón o Arcos, que hasta fines del siglo XV se vieron confinadas al reducido ámbito de sus recintos amurallados.

\section{LA FRONTERA DE PORTUGAL}

El caso de la frontera de Portugal es bien distinto, si bien, el hecho fronterizo influyó de manera decisiva en el proceso de poblamiento de una zona desde el momento de la implantación cristiana sería objeto de disputas entre castellanos y portugueses. Como es sabido, tras unas primeras tensiones, en virtud del tratado de Badajoz de 1267 se llegó al acuerdo de considerar el río Guadiana como la frontera entre Portugal y Castilla. Hubiera sido una solución correcta desde el punto de vista físico de no haber sido por los derechos históricos de la primera sobre algunos territorios situados a la orilla izquierda del río: Serpa, Moura, Moura y Noudar, por supuesto, pero también Aracena y Aroche, conquistadas y repobladas por Alfonso III.

Las primeras declaraciones de intenciones por parte castellana datan de 1253 , cuando Alfonso $X$ atribuyó al concejo de Sevilla todas las tierras conquistadas al este de la línea del Guadiana, incluyendo nominatim a las localidades de Ayamonte, Aracena, Aroche, Serpa, Moura, Frejenal y Jerez de los Caballeros. La solución de compromiso intentada tras la firma del acuerdo de Badajoz, consistente en ceder los territorios disputados a una Orden Militar internacional como la del Hospital, se mantuvo hasta 1271 en Alfonso X recuperó el control directo de Serpa y Moura, pero sin por ello atribuir estos territorios al concejo de Sevilla. En 1283 el rey, consciente de los problemas de integración que suponían los antiguos territorios portugueses incorporados a Castilla tras el tratado de Badajoz, los incorporó, junto con Niebla y otras villas, al señorío personal de su hija la reina doña Beatriz, viuda de Alfonso III de Portugal.

Tal vez esta fórmula hubiera dado sus frutos de haber respetado Sancho IV las disposiciones testamentarias de su padre. No fue así. Y, 
consciente además del problema fronterizo, mantuvo a la zona disputada fuera de la jurisdicción de Sevilla. La ciudad reaccionó prohibiendo a los de Moura y Noudar «vizinar» o tener conmunidad de término con los de Aroche (F. PÉREZ EMBID: La frontera entre los reinos de Sevilla y Portugal, Sevilla 1975, p. 74). Y cuando en 1293 el rey ordenó al concejo hispalense la construcción de una serie de fortalezas para que la sierra estuviese "guardada muy bien» — citando expresamente las de Santa Olalla, Cumbres y Aroche-, no hacia mención alguna a Serpa y Moura. Lo que no significa que tuviese en mente la devolución a Portugal de estos territorios, como se ha afirmado sin demasiado fundamento por parte de algunos historiadores portugueses como Antonio Brandao (Cfr. F. Pérez EmBID Ob. cit., p. 75, nota 93). Pero no ignoraba que, tarde o temprano, el problema volvería a ser planteado. Sabemos, en efecto, que el tratado firmado en Alcañices en 1297 ofreció una solución al conflicto: Serpa y Moura fueron reconocidas por Fernando IV como territorios de la "conquista portuguesa», pero Aracena y Aroche, también reclamadas por D. Doniz, quedaron dentro del reino de Sevilla, compensándose a Portugal por estos territorios con la entrega de Olivenza y Campo Mayor.

Pero, antes de que estallase el conflicto y fuese provisionalmente resuelto, Sancho IV, como indicábamos más arriba, se preocupó por la creación de un sistema defensivo que protegiese el principal acceso a Sevilla desde Portugal. Tal sistema estaba constituido, en palabras de don Francisco Collantes de Terán y Delorme

«por lugares fortificados y castillos de bastante solidez, dada la naturaleza del terreno, formando líneas concéntricas escalonadas en profundidad, de las cuales la primera y más cercana a la frontera la formaban Aroche, Encinasola y Frenegal, teniendo detrás una segunda con Torres, Cortegana y Cumbres Mayores, y por último otra formada por Aracena, Cala y Santa Olalla. El Castillo de las Guardas servía de enlace a estas defensas periféricas con el grupo situado en las cercanías de la capital». («Los castillos del reino de Sevilla», Archivo Hispalense, 58-59, Sevilla 1953, p.19).

La creación de este complejo sistema defensivo fue una tarea lenta y compleja. El documento de 1293 a que hemos aludido sólo cita los castillos de Cumbres, Santa Olalla, Aroche y Frenegal; pero 1344 existían ya, además de éstos, los de las Cumbres de Enmedio, Cumbres de San Bartolomé, Cala. Castilblanco, Castillo de las Guardas, Real de la Jara, Zufre y otros más que no hacen al caso. ¿Qué había sucedido? Creo posible adelantar una hipótesis que explique lo sucedido en el sector 
fronterizo de la Sierra de Aroche, a pesar de la desesperante escasez de documentos sobre esta zona.

A fines del siglo xill la Corona y el concejo de Sevilla, de común acuerdo, impulsaron un proceso de remodelación del poblamiento de las sierras de Aracena y Aroche, territorios entonces muy poco poblados o que habían sido objeto de una repoblación de carácter espontáneo protagonizada por grupos de ganaderos, colmeneros, recolectores de corcho, carboneros..., gente toda de costumbres nómadas y poco arraigada en la zona. A estas circunstancias se añadía que el territorio era un espacio propicio para servir de refugio a bandidos y delincuentes. La presencia de «golfines» en la zona ya en fechas muy tempranas consta a través de las Ordenanzas de Colmeneros, dictadas por Sevilla en 1254, y por una carta de privilegios concedida por Alfonso X a Real de la Jara en 1280. De esta forma, las medidas de Sancho IV favorecieron la concentración de esta población dispersa en los núcleos de población ya existentes 0 en otros que ahora se crean. De esta forma, se originó un interesante proceso de "encastillamiento" que tenía, indudablemente, sus ventajas: conseguir, por un lado, un mayor control sobre una población hasta entonces marginal y en parte desarraigada de la tierra, y, por otro, ampliar el sistema defensivo hasta ahora existente. Además, tratándose de una zona potencialmente conflicitiva, la creación de nuevos núcleos de población y la construcción de fortalezas significaban tomar posesión de tierras disputadas y difíciles de deslindar por falta de accidentes naturales que pudieran servir de frontera. Nada ilustra mejor este aspecto de la realidad física del territorio que consideramos que el topónimo de Sierra de la Contienda con que se designa el sector más disputado de esta zona fronteriza.

Una serie de documentos conservados en el Archivo Nacional de la Torre de Tombo permiten sustentar esta hipótesis. Según uno de ellos, en 1315 estaban ya constituidos y poblados los castillos de Cortegana, Torres y Encinasola, que no aparecen citados en el documento de 1293 (ANTT, gav. XVIII, 9-4). Otro documento posterior arroja alguna luz sobre lo sucedido. Se trata de una investigación realizada en 1346 sobre la delimitación de términos entre los concejos de Sevilla y Aroche, por un lado, y los de Moura y Noudar, por otro (ANTT, gav. XX, 14-1). De las declaraciones de los testigos portugueses se deduce que los castellanos habían ocupado en los años finales del siglo xIII territorios que pertenecían a Portugal. Uno de ellos, Ruy Fernández, escudero, vecino de Moura, declaró que siendo comendador de la villa frey Martín Carnaz se cobraba montazgo «per hua sovereira que chamavan Azinha Solla (En- 
cinasola), e que em aquel tempo nom era aldea pobrada, e que ficava aquel logar hu ora está em termo de Moura». Otro testigo, Pedro Martins d'Alvito, declaró que «sabía Anzinha Solla por termo de Moura, e que sabía Torres que por Termo de Moura, e que sabía hi estar huum freire de Moura pror lo Espital». Y como prueba de la pertenencia de estas tierras a la encomienda de la Orden Hospitalaria, otro testigo llamado don Avril declaró que

«se acordava de cinquoenta anos aca que os de Moura montavam e defendiam por seu termo per los Picotos d'Arouche..., e que vizinhos d'Arouche veerom a fazer pucilgas aa Fonte Cuberta, e que foy hi comendador e que thes derribou as casas e que Ihes queimou hi dous homeens nas pucilgas e lhes cortou as maaos".

Por último, Joham Domínguez, ballestero de Eixzrez, declaró «sabía estar Torres huum freyre do Eespital».

En conclusión, el proceso de «encastillamiento" significó no sólo la reorganización del poblamiento disperso de la zona, y así surgieron, entre otros, los núcleos de Encinasola, Torres (hoy despoblado), Cumbres de Enmedio y Cumbres de San Bartolomé, sino también la ocupación de facto de sectores fronterizos de dudosa pertenencia a Castilla. En cualquier caso, no parece que la zona estuviese muy poblada en el siglo XIV. Otra sería la situación en la centuria siguiente. En efecto, a fines del siglo $x \vee$ la Sierra de Aroche parece haber alcanzado un cierto grado de superpoblación que explicaría las tendencias migratorias, la presión sobre las tierras casi despobladas de Barrancos (Portugal) y el hábitat disperso que presentaba la zona perifronteriza de Aracena y Almonaster a fines de la Edad Media (Cfr. M. GonzÁlez JIMÉNEZ: "Conflictos fronterizos en la Sierra de Aroche", Actas das I Jornadas de Historia Medieval do Algarve e Andaluzia, Loulé 1987, pp.349-358).

Lo curioso de este poblamiento fronterizo es que no conoció ninguna de las exenciones y privilegios característicos de las villas de la frontera granadina: no consta que los pobladores tuviesen de forma permanente beneficios fiscales de ninguna índole, ni exenciones militares ni, menos aún, que los castillos de la zona tuviesen la consideración de lugares de asilo o de "cotos de homicianos". El proceso de agrupamiento de la población se impuso desde arriba, aunque tenía evidentes ventajas para una población dedicada preferentemente a la ganadería, ya que los cas- 
tillos - que físicamente se caracterizan por ser grandes recintos defensivos, del tipo de los «albacares» de época islámica- podían servir en tiempo de guerra de refugios tanto para la población de la zona, como para sus ganados. 
